\title{
Effect of Probiotic and Synbiotic Feeding on Hematological and Biochemical Parameters of Sahiwal Cattle
}

\author{
G. Gujar", V. Kumar, S.C. Goswami and A.K. Jhirwal \\ Department of Livestock Production Management, College of Veterinary and Animal Science, \\ RAJUVAS, Bikaner-334001, India \\ *Corresponding author
}

\section{A B S T R A C T}

Keywords

Biochemical,

Hematological, Probiotic, Sahiwal, Synbiotic

Article Info

Accepted: 18 September 2018 Available Online:

10 October 2018
This study was conducted to evaluate the effect of probiotic and synbiotic supplementation on production performance of lactating Sahiwal cattle in arid region of Rajasthan. Eighteen apparently healthy Sahiwal cows in their second month of lactation were randomly assigned to three groups. One group acted as control and was given basal diet only and the cows in other two groups were supplemented with probiotic and synbiotic at the dose of $15 \mathrm{~g} / \mathrm{animal} / \mathrm{day}$ and 10g/animal/day, for three months. No significant effect of probiotic and synbiotic supplementation was evident on different hematological parameters viz. total leukocyte count of cows and the values of neutrophils, lymphocytes, eosinophils and monocytes were within normal physiological range. The supplementation of probiotic and synbiotic did not have any significant effect on different biochemical parameters serum cholesterol, glucose, calcium and phosphorus levels.

\section{Introduction}

Animal husbandry and dairying along with agriculture forms the backbone of the rural Indian economy. The milk production has increased from 146.3 million tonnes in 201415 to 155.5 in 2015-16 registering a growth of 6.27 per cent, of which 48 per cent is contributed by cattle alone. Sahiwal is one of the established milch cattle breed of tropical regions, with large population concentrated in India and Pakistan. The average lactation yield ranges from $1600-2750 \mathrm{Kg}$ per lactation with average fat percentage ranging from 4.8-5.1 (AGRIS-IS). The major bottleneck in exploiting the full potential of animals is the feeding practices adopted in our country. A lot of research has been done on the various feed additives for livestock feeding from early years. Most of the feed additives used for ruminants are aimed at rumen manipulation mainly to enhance rumen microbial fermentation, predominantly fibre degradation by incorporating such additives which make the ruminal environment favourable for the useful cellulolytic microbes to proliferate and suppress the harmful microbial population.

The joint Food and Agriculture Organization of the United Nations (FAO) and World Health Organization (WHO) working group defined probiotics as "live micro-organisms, which when administered in adequate amounts confer a health benefit on the host" (FAO/ 
WHO, 2001). Adding probiotics to feed for dairy cows leads to an increase in their milkiness and to improved nutrient utilization, due to the stabilization of bacterial microflora in the rumen (Semeniuk et al., 2008). Synbiotics may be defined as a mixture of probiotics and prebiotics that beneficially affects the host by improving the survival and implantation of live microbial dietary supplements in the gastrointestinal tract (Gibson and Roberfroid, 1995). The main aim for using a synbiotic is that a true probiotic, without its prebiotic food, does not survive well in the digestive system. So, taking into consideration the above facts, the present study has been planned to evaluate the effect of Probiotic and Synbiotic feeding on hematological and biochemical parameters of Sahiwal Cattle in the arid area of Rajasthan.

\section{Materials and Methods}

The present study was conducted to evaluate the effects of probiotic and synbiotic supplementation on the production performance of Sahiwal cattle in arid region of Rajasthan. All the work related to this study was carried out at the Livestock Research Station, Kodamdesar and laboratories of Rajasthan University of Veterinary and Animal Sciences, Bikaner.

\section{Selection of animals}

Eighteen healthy Sahiwal cows in their second month of lactation were selected and randomly divided into three groups of six animals each: Group-I was given only basal diet without any supplementation and acted as control group. Group-II and Group-III were supplemented with probiotic and synbiotic, respectively. The data for various observations were recorded after two weeks of acclimatization where treatment groups were fed supplements and continued till the end of third month of experiment. All cows were free from physiological, anatomical and infectious diseases. Animals were housed in well ventilated and protected shed and were allowed to acclimatize for a period of seven day for experimental feeding.

\section{Experimental feeding}

Each animal in control and supplemented groups were offered green fodder $a b l i b$. and $2.5 \mathrm{~kg}$ concentrate mixture daily. $1 \mathrm{~kg}$ extra concentrate mixture was given for every 2.5 $\mathrm{kg}$ milk production. The control group (Group-I) cows daily received the basal diet formulated on the guidelines of NRC, 2001 based on pelleted concentrate feed, green maize and wheat straw and the cow in the other two experimental groups were additionally supplemented with probiotic and synbiotic, respectively.

\section{Amount of probiotic and synbiotic feeding}

The animal were fed with probiotic and symbiotic as given in Table 1.

\section{Composition of basal diet}

The diets of cows were based on green maize, wheat straw and concentrate mixture with proximate principles have been given in Table 2.

The proximate composition of concentrate mixture has been presented in Table 2. Same dry roughage, green and concentrate feed was offered to animals of control and supplemented groups.

\section{Experimental designs}

\section{Time period for sample collection}

All the experimental animals were randomly assigned to three groups having 6 animals in each group as given in Table 3. 


\section{Parameters studied}

\section{Blood parameters}

Total Leukocyte count and Differential leukocyte count.

\section{Serum parameters}

Serum Cholesterol, Glucose, Calcium and Phosphorus.

\section{Collection of samples}

To estimate blood parameters, blood samples were collected on the $15^{\text {th }}, 30^{\text {th }}, 45^{\text {th }}, 60^{\text {th }}, 75^{\text {th }}$ and $90^{\text {th }}$ day respectively after start of experiment period. Blood samples were collected from Jugular vein using sterile needle. Blood samples for serum analysis was collected in clean sterile blood collection vials and those for blood cell counts were collected in vials containing EDTA.

\section{Analysis of the sample}

The samples were brought to the laboratory immediately after collection and blood cell count was carried out. The total leukocyte count was done using a Neubauer chamber/ hemocytometer. Differential leukocyte count was done by preparing a blood smear followed by staining with Geimsa stain and counting the leukocytes under oil immersion lens.

\section{Biochemical analysis}

For serum biochemical analysis, the blood samples were collected fortnightly. The blood for serum analysis was collected in clean sterile blood collection tubes and was immediately placed on ice. After completion of sample collection, the samples were centrifuged at $3000 \mathrm{rpm}$ for 15 minutes, the serum so separated was then collected in clean sterile serum tubes and stored in deep freezer till further analysis. The serum samples were subjected to biochemical analysis for estimation of serum glucose, cholesterol, calcium and phosphorus. The serum analysis for these parameters was done by Idexx chemistry analyzer machine using vet test kits supplied by Idexx laboratories, as per procedure outlined by the manufacturers.

\section{Results and Discussion}

\section{Serum parameters}

The various serum parameters studied and recorded during the experimental period has been presented in the following subsections:

\section{Serum cholesterol}

The overall average serum cholesterol levels recorded during the duration of experiment were $77.81 \pm 2.302,78.80 \pm 1.591$ and $78.89 \pm$ 1.415 in control, probiotic and synbiotic supplemented groups, respectively. In this study, both the supplemented groups had higher cholesterol levels in serum compared to the control cows. But the increase in serum cholesterol level was statistically nonsignificant as evident from Table 4 and 5.

Our results concur with the findings of Morsy et al., (2014) and Dehghan-Banadaky et al., (2012).

\section{Serum glucose}

The overall average serum glucose levels of control, probiotic and synbiotic supplemented groups during the course of experiment were $59.64 \pm 1.037,62.88 \pm 2.079$ and $62.35 \pm$ 1.457 , respectively. The difference in overall average serum glucose levels between control and supplemented groups was non-significant [Table 4 and 5] during the course of this study. Highest serum glucose level $(62.88 \mathrm{mg} / \mathrm{dl})$ was recorded in probiotic fed group followed 
by synbiotic fed group $(62.35 \mathrm{mg} / \mathrm{dl})$, while control cows had the lowest $(59.64 \mathrm{mg} / \mathrm{dl})$ serum glucose level. But the differences in glucose levels were statistically not significant and the glucose levels were within normal physiological values for all groups.

Similar to our findings were reported by Morsy et al., (2014), El-Din (2015), Yalçın et al., (2011) and Bruno et al., (2009) who also reported no significant effects of probiotic on serum glucose levels.

\section{Serum calcium}

The overall average serum calcium levels (Table 4) of control, probiotic and synbiotic supplemented groups during the course of experiment were $9.64 \pm 0.385,9.53 \pm 0.335$ and $9.34 \pm 0.266$, respectively. Statistical analysis (Table 5) revealed non-significantly lower values of overall average serum calcium level in both supplemented groups with the synbiotic supplemented group having lowest serum calcium level.

Similar findings were obtained by Kocabagli et al., (2001) and Sretenovic et al., (2008).

\section{Serum phosphorus}

The overall average serum phosphorus levels as shown in Table 6 during the experimental period were $5.81 \pm 0.288,5.87 \pm 0.304$ and $5.78 \pm 0.334$ in control, probiotic and synbiotic supplemented groups, respectively. Statistical analysis (Table 7) revealed nonsignificantly higher overall average serum phosphorus levels in both the supplemented groups compared to control groups.

Zaworski et al., (2014) reported a significant increase in serum phosphorus levels of cows fed probiotic supplemented diets.

Table.1 Supplementation of probiotics and synbiotic in experimental animals

\begin{tabular}{|l|l|l|l|}
\hline Groups & No. of Animals & Treatment & Dose/Animal/day \\
\hline Control & 6 & Nil & Control \\
\hline Supplemented With Probiotic & 6 & Probiotic & $15 \mathrm{~g} / \mathrm{animal} / \mathrm{day}$ \\
\hline Supplemented With Synbiotic & 6 & Synbiotic & $10 \mathrm{~g} / \mathrm{animal} / \mathrm{day}$
\end{tabular}

Table.2 Proximate analysis of feeds given to experimental animals

\begin{tabular}{|l|l|l|l|}
\hline Nutrients (Per cent) & Wheat straw & Green maize & Concentrate mixture \\
\hline DM & 91.50 & 27.80 & 89 \\
\hline CP & 3.20 & 6.54 & 20 \\
\hline CF & 29.82 & 27.52 & 10 \\
\hline EE & 0.30 & 1.27 & 4.31 \\
\hline Ash & 12.31 & 11.82 & 4.92 \\
\hline
\end{tabular}

Table.3 To study the effect of supplementation of probiotic and symbiotic on the blood parameters of Sahiwal cow

\begin{tabular}{|l|l|l|}
\hline GROUP 1 (control cows) $n=6$ & $\begin{array}{l}\text { GROUP 2 (supplemented } \\
\text { cows) } n=6\end{array}$ & $\begin{array}{l}\text { GROUP 3 (supplemented } \\
\text { cows) } n=6\end{array}$ \\
\hline Basal diet only & Basal diet + Probiotic & Basal diet + Synbiotic \\
\hline
\end{tabular}


Table.4 Mean $( \pm \mathrm{SE})$ of fortnightly serum cholesterol $(\mathrm{mg} / \mathrm{dl})$, serum glucose and serum calcium in control and supplemented cows

\begin{tabular}{|c|c|c|c|c|c|c|c|c|c|}
\hline \multirow[b]{2}{*}{ FORTNIGHTS } & \multicolumn{3}{|c|}{ Serum cholesterol } & \multicolumn{3}{|l|}{ Serum glucose } & \multicolumn{3}{|c|}{ Serum calcium } \\
\hline & CONTROL & PROBIOTIC & SYNBIOTIC & CONTROL & PROBIOTIC & SYNBIOTIC & CONTROL & PROBIOTIC & SYNBIOTIC \\
\hline 1 & $77.45 \pm 2.667$ & $78.15 \pm 1.669$ & $78.51 \pm 1.420$ & $58.26 \pm 1.274$ & $61.92 \pm 2.163$ & $61.96 \pm 1.610$ & $9.53 \pm 1.125$ & $9.52 \pm 1.054$ & $9.29 \pm 0.754$ \\
\hline 2 & $77.31 \pm 2.247$ & $78.87 \pm 1.619$ & $78.82 \pm 1.365$ & $59.20 \pm 1.278$ & $62.87 \pm 2.017$ & $62.16 \pm 1.586$ & $9.45 \pm 0.842$ & $9.56 \pm 1.031$ & $9.30 \pm 0.592$ \\
\hline 4 & $77.97 \pm 2.201$ & $79.02 \pm 1.555$ & $78.94 \pm 1.335$ & $60.36 \pm 1.089$ & $63.09 \pm 2.055$ & $62.98 \pm 1.439$ & $9.60 \pm 0.926$ & $9.53 \pm 0.824$ & $9.48 \pm 0.609$ \\
\hline 5 & $78.41 \pm 2.234$ & $79.16 \pm 1.622$ & $79.10 \pm 1.484$ & $60.19 \pm 0.834$ & $63.62 \pm 2.089$ & $62.32 \pm 1.432$ & $9.66 \pm 0.895$ & $9.48 \pm 0.800$ & $9.35 \pm 0.696$ \\
\hline 6 & $77.88 \pm 2.302$ & $78.75 \pm 1.540$ & $78.62 \pm 1.444$ & $60.09 \pm 0.832$ & $62.79 \pm 2.097$ & $62.18 \pm 1.328$ & $9.65 \pm 1.049$ & $9.34 \pm 0.600$ & $9.29 \pm 0.682$ \\
\hline OVERALL & $77.81 \pm 2.302$ & $78.80 \pm 1.591$ & $78.89 \pm 1.415$ & $59.64 \pm 1.037$ & $62.88 \pm 2.079$ & $62.35 \pm 1.457$ & $9.64 \pm 0.385$ & $9.53 \pm 0.335$ & $9.34 \pm 0.266$ \\
\hline
\end{tabular}

Table.5 Analysis of variance of serum cholesterol, serum glucose and serum calcium in control and supplemented cows

\begin{tabular}{|l|l|l|l|l|l|l|l|}
\hline Source & DF & MS & F & MS & F & MS & F \\
\hline Treatment & 2 & 2.149765 & NS & 18.09032 & NS & 0.136462 & NS \\
\hline Error & 15 & 19.67114 & & 15.04828 & & 0.665706 \\
\hline Total & 17 & & & & & \\
\hline
\end{tabular}

Table.6 Mean $\left( \pm\right.$ SE) of fortnightly Serum Phosphorus, Total Leukocyte Count $\left(\times 10^{3}\right) / \mathrm{mm}^{3}$ and blood neutrophil counts $\left(\mathrm{x} 10^{3}\right) / \mathrm{mm}^{3}$ in Control and Supplemented Cow

\begin{tabular}{|c|c|c|c|c|c|c|c|c|c|}
\hline & \multicolumn{3}{|c|}{ Serum phosphorus } & \multicolumn{3}{|c|}{ Total Leukocyte Count $\left(\mathrm{x}^{3} 0^{3}\right) / \mathrm{mm}^{3}$} & \multicolumn{3}{|c|}{ blood neutrophil counts $\left(\mathrm{x}^{3} 0^{3}\right) / \mathrm{mm}^{3}$} \\
\hline FORTNIGHTS & CONTROL & PROBIOTIC & SYNBIOTIC & CONTROL & PROBIOTIC & SYNBIOTIC & CONTROL & PROBIOTIC & SYNBIOTIC \\
\hline 1 & $5.75 \pm 0.859$ & $5.82 \pm 0.767$ & $5.74 \pm 0.847$ & $10.90 \pm 1.824$ & $11.35 \pm 1.590$ & $9.61 \pm 1.862$ & $3.01 \pm 0.693$ & $3.68 \pm 0.246$ & $3.56 \pm 0.598$ \\
\hline 2 & $5.75 \pm 0.776$ & $5.90 \pm 0.740$ & $5.71 \pm 0.839$ & $10.57 \pm 1.898$ & $11.61 \pm 1.832$ & $9.41 \pm 1.998$ & $3.16 \pm 0.832$ & $3.86 \pm 0.266$ & $3.96 \pm 0.600$ \\
\hline 3 & $5.97 \pm 0.698$ & $5.86 \pm 0.754$ & $5.82 \pm 0.869$ & $10.98 \pm 1.579$ & $11.35 \pm 1.384$ & $9.30 \pm 1.620$ & $3.70 \pm 0.180$ & $4.01 \pm 0.157$ & $4.05 \pm 0.388$ \\
\hline 4 & $5.83 \pm 0.741$ & $5.91 \pm 0.734$ & $5.81 \pm 0.804$ & $10.16 \pm 1.320$ & $9.83 \pm 1.371$ & $9.35 \pm 1.254$ & $3.95 \pm 0.251$ & $3.93 \pm 0.098$ & $3.65 \pm 0.076$ \\
\hline 5 & $5.81 \pm 0.643$ & $5.88 \pm 0.751$ & $5.82 \pm 0.778$ & $9.88 \pm 1.163$ & $10.38 \pm 0.823$ & $9.61 \pm 0.831$ & $3.40 \pm 0.315$ & $3.58 \pm 0.190$ & $3.76 \pm 0.154$ \\
\hline 6 & $5.75 \pm 0.606$ & $5.87 \pm 0.738$ & $5.77 \pm 0.787$ & $9.58 \pm 1.103$ & $10.30 \pm 0.724$ & $9.91 \pm 0.952$ & $3.83 \pm 0.280$ & $4.16 \pm 0.135$ & $3.73 \pm 0.181$ \\
\hline OVERALL & $5.81 \pm 0.288$ & $5.87 \pm 0.304$ & $5.78 \pm 0.334$ & $10.34 \pm 1.460$ & $10.80 \pm 1.263$ & $9.53 \pm 1.364$ & $3.51 \pm 0.388$ & $3.87 \pm 0.142$ & $3.78 \pm 0.290$ \\
\hline
\end{tabular}


Table.7 Analysis of variance of serum phosphorus, total leukocyte count and blood neutrophil counts in control and supplemented cows

\begin{tabular}{|l|c|c|c|c|c|c|c|c|}
\hline Source & DF & MS & F & MS & F & MS & F \\
\hline Treatment & 2 & 0.014508 & NS & 2.482758 & NS & 0.216991 & NS \\
\hline Error & 15 & 0.57633 & & 11.18318 & & 0.511633 & \\
\hline Total & 17 & & & & & &
\end{tabular}

Table.8 Mean $\left( \pm\right.$ SE) of fortnightly blood lymphocyte counts $\left(\times 10^{3}\right) / \mathrm{mm}^{3}$, blood monocyte counts $\left(\mathrm{x} 10^{3}\right) / \mathrm{mm}^{3}$ and blood eosinophil counts $\left(\mathrm{x} 10^{3}\right) / \mathrm{mm}^{3}$ in control and supplemented cows

\begin{tabular}{|c|c|c|c|c|c|c|c|c|c|}
\hline \multirow[b]{2}{*}{ FORTNIGHTS } & \multicolumn{3}{|c|}{ blood lymphocyte counts $\left(\times 10^{3}\right) / \mathrm{mm}^{3}$} & \multicolumn{3}{|c|}{ blood monocyte counts $\left(\times 10^{3}\right) / \mathrm{mm}^{3}$} & \multicolumn{3}{|c|}{ blood eosinophil counts $\left(\times 10^{3}\right) / \mathrm{mm}^{3}$} \\
\hline & CONTROL & PROBIOTIC & SYNBIOTIC & CONTROL & PROBIOTIC & SYNBIOTIC & CONTROL & PROBIOTIC & SYNBIOTIC \\
\hline 1 & $3.98 \pm 0.486$ & $3.41 \pm 0.425$ & $5.33 \pm 0.834$ & $0.33 \pm 0.066$ & $0.51 \pm 0.101$ & $0.51 \pm 0.083$ & $1.16 \pm 0.230$ & $0.83 \pm 0.088$ & $0.71 \pm 0.297$ \\
\hline 2 & $3.88 \pm 1.156$ & $4.51 \pm 1.070$ & $5.70 \pm 1.814$ & $0.41 \pm 0.055$ & $0.56 \pm 0.055$ & $0.51 \pm 0.074$ & $0.56 \pm 0.152$ & $1.68 \pm 0.107$ & $0.95 \pm 0.172$ \\
\hline 3 & $5.56 \pm 1.061$ & $6.26 \pm 0.835$ & $6.20 \pm 0.794$ & $0.45 \pm 0.056$ & $0.38 \pm 0.065$ & $0.40 \pm 0.057$ & $1.10 \pm 0.1$ & $0.88 \pm 0.208$ & $0.88 \pm 0.213$ \\
\hline 4 & $5.76 \pm 0.412$ & $6.56 \pm 0.488$ & $6.70 \pm 0.403$ & $0.41 \pm 0.060$ & $0.38 \pm 0.040$ & $0.36 \pm 0.055$ & $0.91 \pm 0.079$ & $1.13 \pm 0.111$ & $1.03 \pm 0.178$ \\
\hline 5 & $6.01 \pm 0.430$ & $6.66 \pm 0.229$ & $6.53 \pm 0.343$ & $0.33 \pm 0.033$ & $0.38 \pm 0.047$ & $0.45 \pm 0.076$ & $0.86 \pm 0.080$ & $1.05 \pm 0.133$ & $0.96 \pm 0.088$ \\
\hline 6 & $5.11 \pm 0.317$ & $6 \pm 0.193$ & $6.08 \pm 0.222$ & $0.35 \pm 0.042$ & $0.41 \pm 0.030$ & $0.45 \pm 0.022$ & $0.91 \pm 0.074$ & $0.98 \pm 0.060$ & $1.01 \pm 0.087$ \\
\hline OVERALL & $5.05 \pm 0.391$ & $5.57 \pm 0.301$ & $6.091 \pm 0.391$ & $0.38 \pm 0.032$ & $0.44 \pm 0.016$ & $0.45 \pm 0.032$ & $0.92 \pm 0.056$ & $1.09 \pm 0.087$ & $0.92 \pm 0.152$ \\
\hline
\end{tabular}

Table.9 Analysis of variance of blood lymphocyte counts, blood monocyte counts and blood eosinophil counts in control and supplemented cows

\begin{tabular}{|l|c|c|c|c|c|c|c|}
\hline Source & DF & MS & F & MS & F & MS & F \\
\hline Treatment & 2 & 1.610293 & NS & 0.007917 & NS & 0.057469 & NS \\
\hline Error & 15 & 0.794892 & & 0.004843 & & 0.068333 & \\
\hline Total & 17 & & & & & & \\
\hline
\end{tabular}




\section{Blood parameters}

\section{Total Leukocyte count}

The overall means for Total leukocyte count as evident from Table 6 were $10.34 \pm 1.460$, $10.80 \pm 1.263$ and $9.53 \pm 1.364$ in the control, probiotic and synbiotic supplemented groups, respectively. Statistical analysis (Table 7) revealed that the total leukocyte count did not differ significantly between control and supplemented groups and between probiotic and synbiotic supplemented groups.

Similar findings were reported by Agazzi et al., (2014) and Kim et al., (2011).

\section{Differential leukocyte count}

The differential leukocyte count of control and supplemented groups has been presented under following sub-sections:

\section{Neutrophil count of blood}

The overall average neutrophil counts were $3.51 \pm 0.388,3.87 \pm 0.142$ and $3.78 \pm 0.290$ $\left(\mathrm{x} 10^{3}\right) / \mathrm{mm}^{3}$ in control, probiotic and synbiotic supplemented groups during the duration of this study (Table 6). Statistical analysis shown in Table 7 revealed non-significant difference in the overall average neutrophil counts between control and supplemented groups and between probiotic and synbiotic supplemented groups.

Consistent with our findings, Agazzi et al., (2014) also reported statistically nonsignificant difference in the values of Neutrophils in probiotic fed cows.

\section{Lymphocyte count of blood}

The overall average lymphocyte counts (Table 8) during the experimental period were $5.05 \pm 0.391,5.57 \pm 0.301$ and $6.091 \pm 0.391$ in control, probiotic and synbiotic supplemented groups, respectively. The overall average lymphocyte count did not differ significantly (Table 9) between the control and supplemented groups and between the supplemented groups.

Similar results was reported by Agazzi et al., (2014) also reported statistically nonsignificant difference in the values of Lymphocytes in probiotic fed cows, which concurs with our results.

\section{Monocyte count of blood}

The overall average monocyte counts (Table 8 ) were recorded as $0.38 \pm 0.032,0.44 \pm$ 0.016 and $0.45 \pm 0.032$ in control, probiotic and synbiotic supplemented groups, respectively.

Statistical analysis (Table 8) revealed nonsignificant difference in overall average monocyte counts among control and supplemented groups and between both the supplemented groups.

Consistent with this result was reported by Agazzi et al., (2014).

\section{Eosinophil count of blood}

The eosinophil counts during the experimental period were $0.92 \pm 0.056,1.09 \pm$ 0.087 and $0.92 \pm 0.152$ in control, probiotic and synbiotic supplemented groups, respectively (Table 8). Statistical analysis (Table 9) revealed that the difference between overall average eosinophil counts was nonsignificant between control and supplemented groups and between both the supplemented groups.

However, Contradictory findings were reported by Agazzi et al., (2014) and Ghazanfer et al., (2015). 
The supplementation of probiotics and synbiotics did not reveal any significant effects on blood cell counts and serum biochemistry. However, the result revealed non-significant decline in serum calcium it may be due to enhanced milk yield by feeding of probiotic and symbiotic supplements in Sahiwal cattle.

\section{References}

Agazzi A., Tirloni E., Stella S., Maroccolo S., Ripamonti B., Bersani C., Caputo J. M., Dell'Orto V., Rota N., and Savoini G. 2014. Effects of species-specific probiotic addition to milk replacer on calf health and performance during the first month of life. Ann. Anim. Sci., 14(1): 101-115.

Bakr H.A., Hassan M.S., Giadinis N.D., Panousis N., Andrić D.O., Abd ElTawab M.M. and Bojkovski J. 2015. Effect of Saccharomyces Cerevisiae Supplementation on Health and Performance of Dairy Cows during Transition and Early Lactation Period. Biotech. Anim. Husb., 31(3):349-364.

Bruno R.G.S., Rutigliano H.M., Cerri R.L., Robinson P.H. and Santos J.E.P. 2009. Effect of feeding Saccharomyces cerevisiae on performance of dairy cows during summer heat stress. Anim. Feed Sci. Technol., 150:175-186.

Dehghan-Banadaky M., Ebrahimi M., Motameny R. and Heidari S.R. 2012. Effects of live yeast supplementation on mid-lactation dairy cows performances, milk composition, rumen digestion and plasma metabolites during hot season. J. Appl. Anim. Res., 41:137-142.

Deng Q., Odhiambo J.F., Farooq U., Lam T., Dunn S.M., and Ametaj B.N. 2016. Intravaginal probiotics modulated metabolic status and improved milk production and composition of transition dairy cows. J. Anim. Sci., 94:760-770.

Doležal P., Dvořáček J., Doležal J., Čermáková J., Zeman, L. and Szwedziak K. 2011. Effect of feeding yeast culture on ruminal fermentation and blood indicators of Holstein dairy cows. Acta. Veterinaria Brno., 80(2): 139-145.

El-Din N.A. 2015. Milk production and some blood metabolite responses to yeast supplementation in early lactating holstein dairy cows. Egyptian J. Anim. Prod., 52:11-17.

FAO Animal Production and Health, 2016 Probiotics in Animal Nutrition: Production, impact and regulation. 179:5.

Ghazanfar S., Anjum M.I., Azim A. and Ahmed I. 2015. Effects of dietary supplementation of yeast (Saccharomyces cerevisiae) culture on growth performance, blood parameters, nutrient digestibility and fecal flora of dairy heifers. J. Anim. Plant Sci., 25:539.

Gibson G.R. and Roberfroid M.B. 1995. Dietary Modulation of the Human Colonie Microbiota: Introducing the Concept of Prebiotics. J. Nutr., 125:1401-1412.

Kim M.K., Lee H.G., Park J.A., Kang S.K. and Choi Y.J. 2011. Effect of feeding direct-fed microbial as an alternative to antibiotics for the prophylaxis of calf diarrhea in holstein calves. Asian-Aust. J. Anim. Sci., 24(5):643 - 649.

Kocabagli N., Kahraman R., Abas I., Esecelü H. and Alp M. 2001. The Effects of Supplemental Anionic Salts and Probiotic in Prepartum Diets on Milk Production and Quality and Incidence of Milk Fever in Dairy Cows. Turk. J. Vet. Anim. Sci., 25:743-751.

Morsy T.M., Ebeid H.M., Kholif A.E.K.M., Murad H.A, El-Gawad A.E.R.M.A. and 
Bedawy T.M. 2014. Influence of Propionibacteria Supplementation to Rations on Intake, Milk Yield, Composition and Plasma Metabolites of Lactating Buffalos during Early Lactation. Sci. Int., 2:13-19.

Semeniuk W., Klebaniuk R., Grela E. R 2008. Feed additives in animal nutrition. Alfaalfa in human and animal nutrition. E. R. Grela, Dzierdziówka-Lublin 2008; 139-165.

Sretenovic L, Petrovic M, Aleksic S, Pantelic V, Katic V, Bogdanović V. and Beskorovajni R. 2008. Influence of yeast, probiotics and enzymes in rations on dairy cows performances during transition. Biotechnol. Anim. Husb., 24:33-43.

Yalcin S., Yalcin S., Can P., Gurdal A.O., Bagci C. and Eltan O. 2011. The nutritive value of live yeast culture (saccharomyces cerevisiae) and its effect on milk yield, milk composition and some blood parameters of dairy cows. J. Anim. Sci., 24:1377-1385.

Yuan K., Liang T., Muckey M.B., Mendonça L.G.D., Hulbert L.E., Elrod C.C. and Bradford B.J. 2015. Yeast product supplementation modulated feeding behavior and metabolism in transition dairy cows J. Dairy Sci., 98:532-540

Zaworski E.M., Shriver-Munsch C.M., Fadden N.A., Sanchez W.K., Yoon I. and Bobe G. 2014. Effects of feeding various dosages of Saccharomyces cerevisiae fermentation product in transition dairy cows. J. Dairy Sci., 97(5): 3081 - 3098.

\section{How to cite this article:}

Gujar, G., V. Kumar, S.C. Goswami and Jhirwal, A.K. 2018. Effect of Probiotic and Synbiotic Feeding on Hematological and Biochemical Parameters of Sahiwal Cattle. Int.J.Curr.Microbiol.App.Sci. 7(10): 2332-2340. doi: https://doi.org/10.20546/ijcmas.2018.710.270 